\title{
Change in Coherence of Interannual Variability of Summer Rainfall over the Western Pacific around the Early 2000s: Role of Indo-Pacific Ocean Forcing
}

\author{
ZHUOQI HE \\ State Key Laboratory of Tropical Oceanography, South China Sea Institute of Oceanology, Chinese Academy of Sciences, \\ Guangzhou, and State Key Laboratory of Numerical Modeling for Atmospheric Sciences and Geophysical \\ Fluid Dynamics (LASG), Institute of Atmospheric Physics, Chinese Academy of Sciences, Beijing, China

\section{RENGUANG WU} \\ Center for Monsoon System Research, and State Key Laboratory of Numerical Modeling for Atmospheric Sciences and \\ Geophysical Fluid Dynamics (LASG), Institute of Atmospheric Physics, Chinese Academy of Sciences, Beijing, China
}

(Manuscript received 2 November 2017, in final form 1 February 2018)

\begin{abstract}
The observations show that the covariability between the western North Pacific (WNP) and the South China Sea (SCS) summer rainfall has experienced an obvious weakening since the early 2000s. During the period 1982-2003, the combined north Indian Ocean (NIO), central North Pacific (CNP), and central equatorial Pacific (CEP) sea surface temperature (SST) forcing results in a high coherence between the WNP and SCS summer rainfall variations via a zonally elongated anomalous lower-level cyclone over the western Pacific. During the period 2004-16, the Indian Ocean SST contribution is largely weakened, and the WNP rainfall variability is dominated by the enhanced Pacific SST forcing with an eastward retreated lower-level wind and rainfall anomalies, whereas the SCS rainfall variability is mainly associated with local air-sea interaction processes. The results obtained from observational analysis are supported by numerical experiments with atmospheric and coupled general circulation models. The change in the coherence of interannual summer rainfall variability over the WNP and SCS has important implications for regional climate prediction in South and East Asia.
\end{abstract}

\section{Introduction}

The western Pacific Ocean $\left(0^{\circ}-30^{\circ} \mathrm{N}, 100^{\circ} \mathrm{E}-180^{\circ}\right)$ is a moisture reservoir and heat source for the surrounding regions. Anomalous convective heating over the western Pacific plays an important role in the climate variability over East Asia through modulating atmospheric circulation (Nitta 1987; Huang and Sun 1992; Wu et al. 2003). The atmospheric circulation pattern generated by anomalous heating over the western Pacific may even extend to North America and affect rainfall there (Wang et al. 2001). The atmospheric circulation change induced by anomalous western Pacific heating depends upon the location and extent of anomalous rainfall ( $\mathrm{Wu}$ and Wang 2002). Thus, it is necessary to understand the changes in the coherence of rainfall variations over the western Pacific Ocean and associated factors to help improve the climate prediction and risk management.

Corresponding author: Zhuoqi He, zhuoqi@scsio.ac.cn
The rainfall and circulation changes over the western Pacific are influenced by both local air-sea interaction and remote forcing (Wang et al. 2000; Wu and Kirtman 2007; Xie et al. 2009; He and Wu 2013; He and Wu 2014; Hu et al. 2014; Wu et al. 2014; Wu and Hu 2015; He et al. 2016; $\mathrm{Hu}$ and $\mathrm{Wu}$ 2016; $\mathrm{Wu}$ and $\mathrm{He}$ 2017). El Niño events generate an anomalous anticyclone over the western Pacific by compensating descent motion, which is then maintained via a positive thermodynamic feedback (Wang et al. 2000; Wang and Zhang 2002). The tropical Indian Ocean warming in the El Niño decaying summer favors the development of an anomalous anticyclone over the western Pacific through a Kelvin wave response (Xie et al. 2009; Du et al. 2009) or a west-east overturning circulation ( $\mathrm{He}$ and $\mathrm{Wu} 2014 ; \mathrm{He}$ et al. 2016). The tropical central Pacific sea surface temperature (SST) warming induces above-normal rainfall over the western Pacific via a Rossby wave response to anomalous heating ( $\mathrm{He}$ and $\mathrm{Wu} 2014)$. The western North Pacific SST anomaly is capable of inducing 
anomalous rainfall by destabilizing the lower troposphere (Wu and Wang 2002). The rainfall variation in the South China Sea is under the influence of a sequence of coupled processes between atmosphere and SST ( He and $\mathrm{Wu} 2013$; Wu and $\mathrm{Hu} 2015$; $\mathrm{Hu}$ and $\mathrm{Wu} 2016$ ). The magnitude of rainfall anomalies may depend upon the configuration of SST anomalies in different regions $(\mathrm{Hu}$ et al. 2014; Wu et al. 2014).

As the rainfall variations over the western Pacific subject to influences of different factors, the extent and shape of rainfall anomalies may vary from year to year depending upon how the different factors work either individually or in conjunction with each other. This may in turn lead to different convection and circulation patterns over the western Pacific, which correspondingly results in different impacts on the climate variability in remote regions. Previous studies mostly consider the western Pacific region as a whole and pay less attention to changes in the shape and location of circulation and rainfall pattern in this region. Is there a significant change in coherence of rainfall variations over the western Pacific, and if so, what are the possible causes? The above questions, up to now, remain to be answered.

The present study will, for the first time, investigate the recent shift in the rainfall anomaly pattern over the western Pacific during boreal summer, and unravel the possible roles of the shifted Indian and Pacific Ocean remote forcing. Section 2 presents the datasets and methods used in the study. Section 3 investigates the western Pacific summer rainfall variability and detects the period when the summer rainfall pattern changes significantly. Section 4 explores the possible causes for the change in the western Pacific rainfall pattern. Section 5 conducts numerical model experiments to support the proposed physical mechanism. A summary and discussion are given in section 6 .

\section{Data and model}

The monthly mean SST is obtained from the National Oceanic and Atmospheric Administration (NOAA) optimum interpolation (OI) version 2 dataset (Reynolds et al. 2002; http://www.esrl.noaa.gov/psd/ data/gridded/data.noaa.oisst.v2.html) on a $1^{\circ} \times 1^{\circ}$ grid. The monthly mean precipitation is obtained from the Global Precipitation Climatology Project (GPCP), version 2.2, dataset (Adler et al. 2003; http://www.esrl. noaa.gov/psd/data/gridded/data.gpcp.html) on a $2.5^{\circ} \times$ $2.5^{\circ}$ grid. The monthly mean wind is obtained from the National Centers for Environmental Prediction (NCEP)-Department of Energy (DOE) Reanalysis 2 (Kanamitsu et al. 2002; http://www.esrl.noaa.gov/psd/data/ gridded/data.ncep.reanalysis $2 . \mathrm{html}$ ) on a $2.5^{\circ} \times 2.5^{\circ}$ grid.
The present analysis is based on the time period from January 1982 through December 2016. The data are linearly interpolated onto a $1^{\circ} \times 1^{\circ}$ grid, the same resolution as the NOAA OI SST. Seasonal anomalies are derived by subtracting the climatological seasonal cycle from individual seasonal means. All SST and precipitation indices are detrended before the analysis. The empirical orthogonal function (EOF) analysis is adopted to extract the dominant modes of precipitation variations over the western Pacific Ocean. The correlation and regression analysis is employed to identify factors of the western Pacific summer rainfall variability. The composite analysis is used to obtain anomalies in different types of years. The Student's $t$ test is employed to estimate the statistical significance for correlation and composite analysis.

We use the Community Earth System Model (CESM), version 1.0.4, to conduct numerical experiments to examine the atmospheric responses to different SST anomalies. CESM is a fully coupled climate model for simulating Earth's past, present, and future climate system. There are five component models in CESM, including the atmosphere model, the Community Atmosphere Model (CAM), version 4.0; the ocean model, the Parallel Ocean Program, version 2 (POP2); the land model, the Community Land Model (CLM); the land ice model, the Community Ice Code (CICE4); and the sea ice model, the Community Ice Sheet Model (Glimmer-CISM); plus one central coupler component (Vertenstein et al. 2011). The model is widely applied in the research of climate change and monsoon variability and it is demonstrated to be practicable to study the tropical air-sea interaction processes ( $\mathrm{He}$ and $\mathrm{Wu} 2013,2014$; He et al. 2016). In the present study, both the atmosphere and ocean components are employed to conduct numerical experiments. The atmosphere model, developed by the Atmosphere Model Working Group (AMWG), is configured with 26 hybrid sigma levels on a $1.9^{\circ} \times 2.5^{\circ}$ finite volume grid (Eaton 2012). It can be used as standalone model with prescribed sea ice and SST, or coupled with the ocean model in which the ocean component responds to forcing from the atmosphere component. The ocean model (POP2) is an extension of the ocean general circulation model originally developed at Los Alamos National Laboratory (Smith et al. 2010). It solves the three-dimensional primitive equations for fluid motions under hydrostatic and Boussinesq approximations. POP2 handles dipole and tripole grids for the horizontal grid with the pole singularities centered over land and a fixed Eulerian grid for the vertical grid with depth as the vertical coordinate. Detailed descriptions of the numerical discretizations and methods are described by Smith et al. (2010), Vertenstein et al. (2011), and Eaton (2012). 

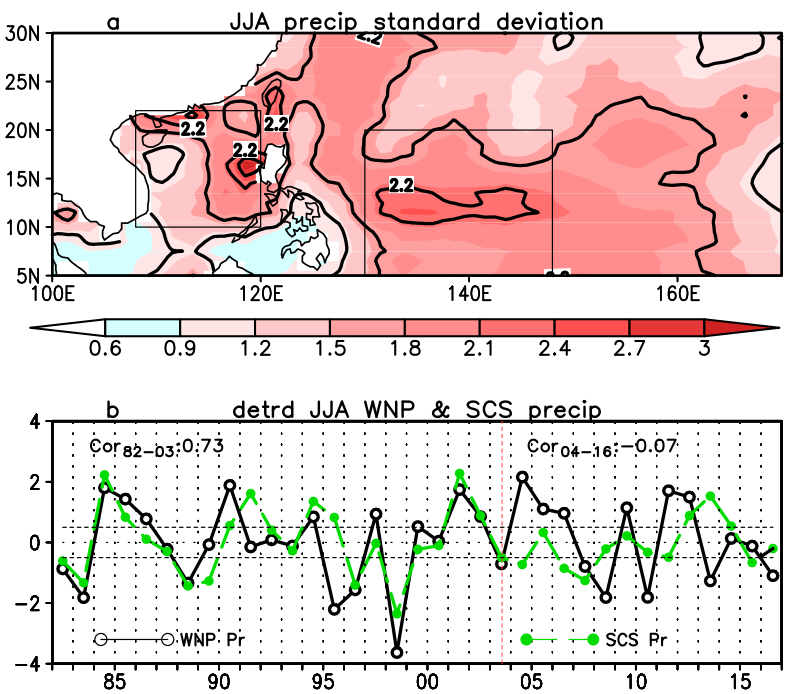

FIG. 1. (a) The standard deviation of summer precipitation anomalies $\left(\mathrm{mm} \mathrm{day}^{-1}\right)$ based on the period 1982-2016. (b) The time series of detrended JJA-mean WNP $\left(5^{\circ}-20^{\circ} \mathrm{N}, 130^{\circ}-148^{\circ} \mathrm{E}\right)$ (black solid) and SCS $\left(10^{\circ}-22^{\circ} \mathrm{N}, 108^{\circ}-120^{\circ} \mathrm{E}\right)$ (green dashed) precipitation anomalies $\left(\mathrm{mm} \mathrm{day}^{-1}\right)$. Boxes in (a) denote the regions to define the WNP summer rainfall index and the SCS summer rainfall index. A value of $\pm 0.5 \mathrm{~mm} \mathrm{day}^{-1}$ (horizontal black dashed) is shown in (b) as the criterion for abnormal rainfall index. The vertical dashed red line in (b) signifies the point after which the WNP-SCS summer rainfall relationship significantly changed with the corresponding correlation coefficients for the two periods shown at top of the panel.

\section{Change in the summer rainfall anomaly pattern}

Figure 1a presents the standard deviation of the JuneAugust (JJA) rainfall anomalies for the period 19822016. The summer rainfall anomalies exhibit the highest variance in the lower-latitude western North Pacific and along the west coast of Philippines and the coast of southern China. To examine the coherency of summer rainfall variations, we selected two regions, one in the western North Pacific (WNP; $\left.5^{\circ}-20^{\circ} \mathrm{N}, 130^{\circ}-148^{\circ} \mathrm{E}\right)$ and the other in the South China Sea (SCS; $10^{\circ}-22^{\circ} \mathrm{N}, 108^{\circ}-$ $\left.120^{\circ} \mathrm{E}\right)$. The above two regions encompass the regions of large rainfall variance. The detrended JJA-mean rainfall anomalies in the SCS and the WNP are shown in Fig. 1b. A feature to be noted is that the coherence between the SCS and WNP summer rainfall variations seems to be largely weakened since the early 2000s. If we consider $2003 / 04$ as the point of change, the correlation coefficient between the two time series is 0.72 for the period $1982-2003$ but drops to -0.07 for the period 2004-16. The Tropical Rainfall Measuring Mission (TRMM) precipitation data are employed for verification and the results show highly consistency among different datasets (figures not shown).
The change in the coherence is further indicated by comparing the statistics of abnormal rainfall years between the two periods. Here, we set the criterion of $\pm 0.5 \mathrm{~mm} \mathrm{day}^{-1}$ for an abnormal rainfall, and define that the SCS and WNP rainfall variations are coherent when the two rainfall indices show same-sign anomalies with the magnitude exceeding $0.5 \mathrm{~mm} \mathrm{day}^{-1}$ and that they are disparate when either of the two rainfall indices exceeds $\pm 0.5 \mathrm{~mm} \mathrm{day}^{-1}$ and meanwhile they show opposite-sign anomalies. The corresponding abnormal years are listed in Table 1 . Before 2003, there are 11 coherent years and 3 disparate years, whereas after 2004, the same-sign cases are largely reduced with only 2 coherent years and the disparate cases increase up to 4 years. The above statistics confirms that the relationship between the SCS and WNP summer rainfall variations has significantly changed in the recent decade.

This weakened SCS-WNP rainfall relationship in the recent decade is illustrated by a shift in the distribution of rainfall and associated circulation pattern. Figure 2 shows the simultaneous correlations of rainfall and $850-\mathrm{hPa}$ wind with respect to the first EOF mode of summer rainfall anomaly over the domain of $5^{\circ}-25^{\circ} \mathrm{N}, 105^{\circ}-160^{\circ} \mathrm{E}$ for the period $1982-2003$ and 2004-16, respectively. In the prior-to-2003 epoch, same-sign rainfall anomalies are observed along an elongated zonal band covering both the WNP and SCS (Fig. 2a). The anomalous cyclone extends from the WNP into the SCS (Fig. 2a). In contrast, in the post2004 epoch, the cyclonic anomaly shrinks in the zonal direction but expands northward to Japan (Fig. 2b). Positive rainfall anomalies are located in the WNP, southern Japan, and South Korea, and negative precipitation anomalies in the southern China and the Maritime Continent. Rainfall anomalies are negative in most of the SCS (Fig. 2b).

The above results suggest that the changed SCS-WNP rainfall relationship is associated with an eastward shift of circulation anomaly pattern over the western Pacific Ocean. The anomalous flow to the northwest of the anomalous anticyclone is important in determining the moisture transport to East Asia (Chang et al. 2000; Wang et al. 2000). The extent of westward extension of the anomalous cyclone (or anticyclone) leads to a great difference in rainfall anomalies in the Indochina Peninsula, southern China, South Korea, and Japan (Figs. 2a,b). This indicates a change in the relationship of rainfall anomalies in these regions with the WNP rainfall anomalies. Hence, revealing the factors for changes in coherence of the summer rainfall variability over the western Pacific since the early 2000s is important for understanding regional climate variability. 
TABLE 1. Relationships between the JJA WNP and SCS rainfall anomalies compared with the JJA central equatorial Pacific (CEP), the JJA central North Pacific (CNP), and the JJA north Indian Ocean (NIO) SST anomalies for the periods 1982-2003 and 2004-16. Plus (minus) signs indicate positive (negative) rainfall and SST anomalies, and "0" represents small anomalies based on the criterion of $\pm 0.5 \mathrm{~mm} \mathrm{day}^{-1}$ or $\pm 0.3 \mathrm{~K}$. Also, $\mathrm{C} \sqrt{ }$ or $\mathrm{N} \sqrt{ }(\mathrm{I} \sqrt{ })$ denotes the years with a same-sign (opposite sign) relationship of the JJA WNP rainfall with the JJA CEP or CNP (NIO) SST anomalies. Years with disparate WNP-SCS rainfall relationship are highlighted in boldface.

\begin{tabular}{|c|c|c|c|c|c|c|c|c|c|c|c|c|c|c|c|c|c|c|c|c|}
\hline \multirow[b]{2}{*}{ Index } & \multicolumn{20}{|c|}{ Year } \\
\hline & 1982 & 1983 & 1984 & 1985 & 1988 & 1990 & 1991 & 1994 & 1995 & 1996 & 1997 & 1998 & 2001 & 2002 & 2004 & 2006 & 62007 & 2011 & 2012 & 2013 \\
\hline $\mathrm{WNP}_{\text {prcp }}$ & - & - & + & + & - & + & 0 & + & - & - & + & - & + & + & + & + & - & + & + & - \\
\hline $\mathrm{SCS}_{\mathrm{prcp}}$ & - & - & + & + & - & + & + & + & + & - & 0 & - & + & + & - & - & - & - & + & + \\
\hline $\mathrm{JJA} \mathrm{CEP}_{\mathrm{SST}}$ & + & 0 & - & - & - & 0 & + & + & 0 & 0 & + & - & 0 & + & + & + & 0 & - & 0 & - \\
\hline JJA NIO $_{\mathrm{SST}}$ & 0 & + & - & - & + & 0 & $\mathbf{0}$ & - & 0 & 0 & $\mathbf{0}$ & + & 0 & 0 & $\mathbf{0}$ & $\mathbf{0}$ & 0 & $\mathbf{0}$ & 0 & - \\
\hline $\mathrm{JJA} \mathrm{CNP}_{\mathrm{SST}}$ & 0 & - & + & 0 & 0 & 0 & $\mathbf{0}$ & + & $\mathbf{0}$ & + & $\mathbf{0}$ & - & + & 0 & 0 & $\mathbf{0}$ & 0 & $\mathbf{0}$ & 0 & $\mathbf{0}$ \\
\hline Contribution & & $\mathrm{I} \sqrt{ } \mathrm{N} \sqrt{ }$ & $\mathrm{I} \sqrt{ } \mathrm{N} \sqrt{ }$ & $\mathrm{I} \sqrt{ }$ & $\mathrm{I} \sqrt{ } \mathrm{C} \sqrt{ }$ & & & $\mathrm{I} \sqrt{ } \mathrm{C} \sqrt{ } \mathrm{N} \sqrt{ }$ & & & $\mathrm{C} \sqrt{ }$ & $\mathrm{I} \sqrt{ } \mathrm{C} \sqrt{ } \mathrm{N} \sqrt{ }$ & $\mathrm{N} \sqrt{ }$ & $\mathrm{C} \sqrt{ }$ & $\mathrm{C} \sqrt{ }$ & $\mathrm{C} \sqrt{ }$ & & & & $\mathbf{C} \sqrt{ }$ \\
\hline
\end{tabular}

\section{Changes in local and remote influence around the early 2000s}

Section 3 suggests that the SCS and WNP summer rainfall variations are dissimilar and the large-scale circulation pattern changes after 2003/04. This phenomenon raises a question: What are the causes for this change? In this section, we explore the possible reasons for the WNP and SCS rainfall changes in two periods separately.

\section{a. Changes in the tropical ocean forcing for the WNP summer rainfall}

Figure 3 presents simultaneous regression of precipitation, lower-level wind, and SST with respect to the JJA WNP rainfall anomalies for the periods 19822003 and 2004-16. Before 2003/04, the rainfall anomaly distribution features a north-south tripole pattern over the domain $15^{\circ} \mathrm{S}-40^{\circ} \mathrm{N}, 70^{\circ} \mathrm{E}-180^{\circ}$ (Fig. 3a). Precipitation anomalies in the SCS are of the same sign as those in the WNP, accompanied by a zonally elongated lower-level cyclonic anomaly. The SST anomalies feature a west-east contrast between the north Indian Ocean and the central North Pacific along with positive SST anomalies in the equatorial central Pacific (Fig. 3b). The role of the east-west SST anomaly pattern in the formation of lower-level anomalous cyclone and positive rainfall anomalies over the SCS-western Pacific has been demonstrated by Wu et al. (2014) using numerical model experiments. Here, we highlight three key regions where ocean warming or cooling may be responsible for the WNP rainfall variability (boxed areas in Fig. 3b). The first one is the central North Pacific $\left(\mathrm{CNP} ; 12.5^{\circ}-17.5^{\circ} \mathrm{N}, 150^{\circ}-170^{\circ} \mathrm{E}\right)$, the second is the central equatorial Pacific $\left(\mathrm{CEP} ; 5^{\circ} \mathrm{S}-5^{\circ} \mathrm{N}, 160^{\circ} \mathrm{E}-\right.$ $130^{\circ} \mathrm{W}$ ), and the third is the north Indian Ocean (NIO; $\left.10^{\circ}-20^{\circ} \mathrm{N}, 50^{\circ}-100^{\circ} \mathrm{E}\right)$.

In the CNP, positive SST anomalies are overlaid by positive rainfall anomalies extending westward (Figs. 3a,b). The relationship indicates a role of SST forcing. The warmer ocean surface can destabilize the lower troposphere via turbulent heat fluxes and strengthen the moist convection through lower-level moisture convergence, thereby creating conducive condition for enhancing

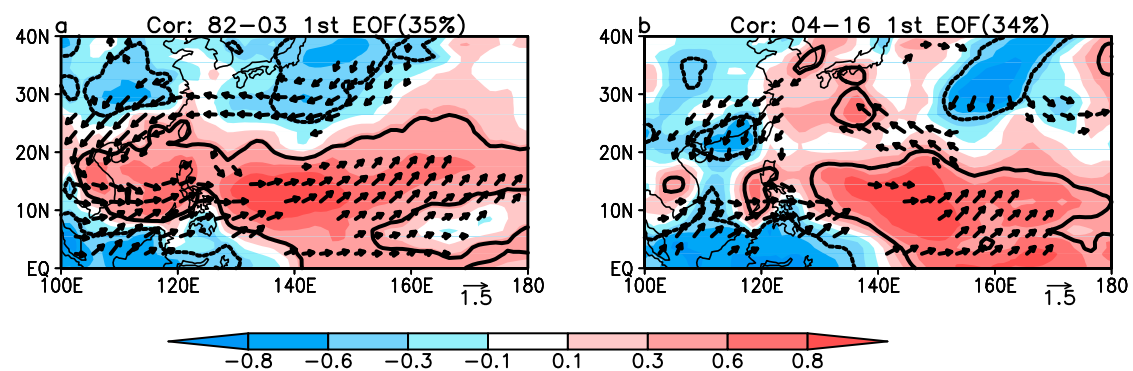

FIG. 2. (a) Simultaneous correlation of precipitation $\left(\mathrm{mm} \mathrm{day}^{-1}\right)$ and $850-\mathrm{hPa}$ wind $\left(\mathrm{m} \mathrm{s}^{-1}\right.$, vector) anomalies with the first EOF principal component of western Pacific summer rainfall anomaly for the period 1982-2003. (b) As in (a), but for the period 2004-16. Thick contours and plotted vectors indicate that the rainfall and wind anomalies are statistically significant at the $90 \%$ confidence level. The scale for wind vectors is given at the bottom right of the respective panel. The numbers in the parentheses denote the percent variance explained by the EOF1 mode. 

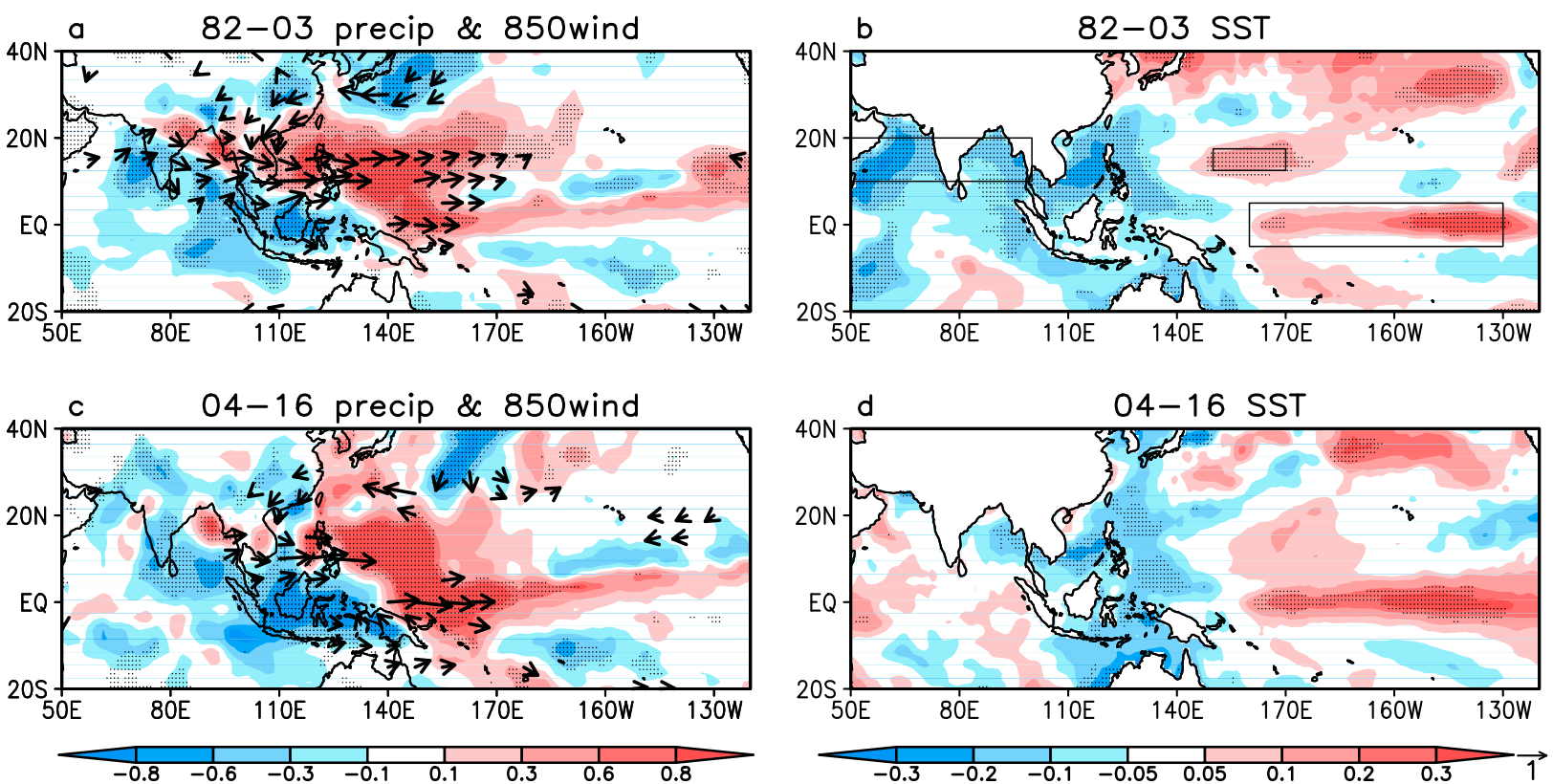

FIG. 3. Simultaneous regression with respect to the WNP summer rainfall index: (a) precipitation (mm day ${ }^{-1}$; shading) and 850 -hPa wind anomalies ( $\mathrm{m} \mathrm{s}^{-1}$; vector) and (b) SST anomalies (K) for the period 1982-2003. (c),(d) As in (a),(b), but for the period 2004-16. Stippling indicates that SST or rainfall anomalies are statistically significant at the $90 \%$ confidence level. Only wind anomalies that are significant at the $90 \%$ confidence level are plotted. The scale for wind vectors is given at the bottom right. Boxes denote the key regions used to define SST indices over the NIO $\left(10^{\circ}-20^{\circ} \mathrm{N}, 50^{\circ}-100^{\circ} \mathrm{E}\right)$, the $\mathrm{CNP}\left(12.5^{\circ}-17.5^{\circ} \mathrm{N}, 150^{\circ}-170^{\circ} \mathrm{E}\right)$, and the $\mathrm{CEP}\left(5^{\circ} \mathrm{S}-5^{\circ} \mathrm{N}, 160^{\circ} \mathrm{E}-\right.$ $\left.130^{\circ} \mathrm{W}\right)$.

local precipitation (Lindzen and Nigam 1987). The impact of CNP SST anomalies on the SCS-Philippine Sea rainfall is demonstrated by atmospheric model experiments with specified SST forcing (Wu et al. 2014).

In the CEP, positive SST anomalies (Fig. 3b) are present with westerly wind anomalies to the west and above-normal precipitation over the WNP (Fig. 3a). According to Matsuno (1966) and Gill (1980), the equatorial warming can excite a Rossby wave-type response with anomalous westerlies and convergence forming to the northwest and southwest sides of the warming. The wind anomaly pattern over the CEP signifies that the CEP heating may contribute to the WNP summer rainfall through the Rossby wave-induced Ekman convergence. Such an effect is verified through numerical model experiment by $\mathrm{He}$ and $\mathrm{Wu}$ (2014).

In the NIO, negative SST anomalies are observed (Fig. 3b). The negative NIO SST anomalies are accompanied by below-normal precipitation over the NIO and above-normal precipitation in the western Pacific, along with anomalous lower-level westerlies over $70^{\circ} \mathrm{E}-180^{\circ}$ (Fig. 3a). According to $\mathrm{He}$ and $\mathrm{Wu}$ (2014), surface cooling in the NIO can lead to compression of the atmospheric column with higher surface pressure. This local cooling effect correspondingly drives anomalous vertical circulation with descending motion over the
NIO and ascending motion over the western Pacific, which favors the development of lower-level convergence and increased summer rainfall over the western Pacific. Similar results were obtained in numerical model experiments conducted by Wu et al. (2014). The observed atmosphere-ocean relationship over the NIO (Figs. 3a,b) validates the remote influence of the NIO SST anomalies on the WNP rainfall anomaly.

After 2003/04, positive rainfall anomalies retreat eastward away from the SCS and are increased near the equatorial western Pacific (Fig. 3c). The rainfall anomaly distribution over the tropical Indo-Pacific features a west-east contrast pattern. SST anomalies are weak in the Indian Ocean (Fig. 3d). SST anomalies in the equatorial Pacific become larger. According to these changes, it may be preliminarily inferred that during the period 2004-16 the WNP summer rainfall variation has a weakened teleconnection with the Indian Ocean SST anomalies and is subject to an enhanced effect of the Pacific Ocean SST anomalies.

To contrast the oceanic forcing during these two periods, we perform a composite analysis based on the 11 abnormal years with same-sign WNP-SCS rainfall relationships for the period 1982-2003 and the 4 abnormal years with opposite-sign relationships for the period 2004-16 (Table 1). The composite anomalies are 

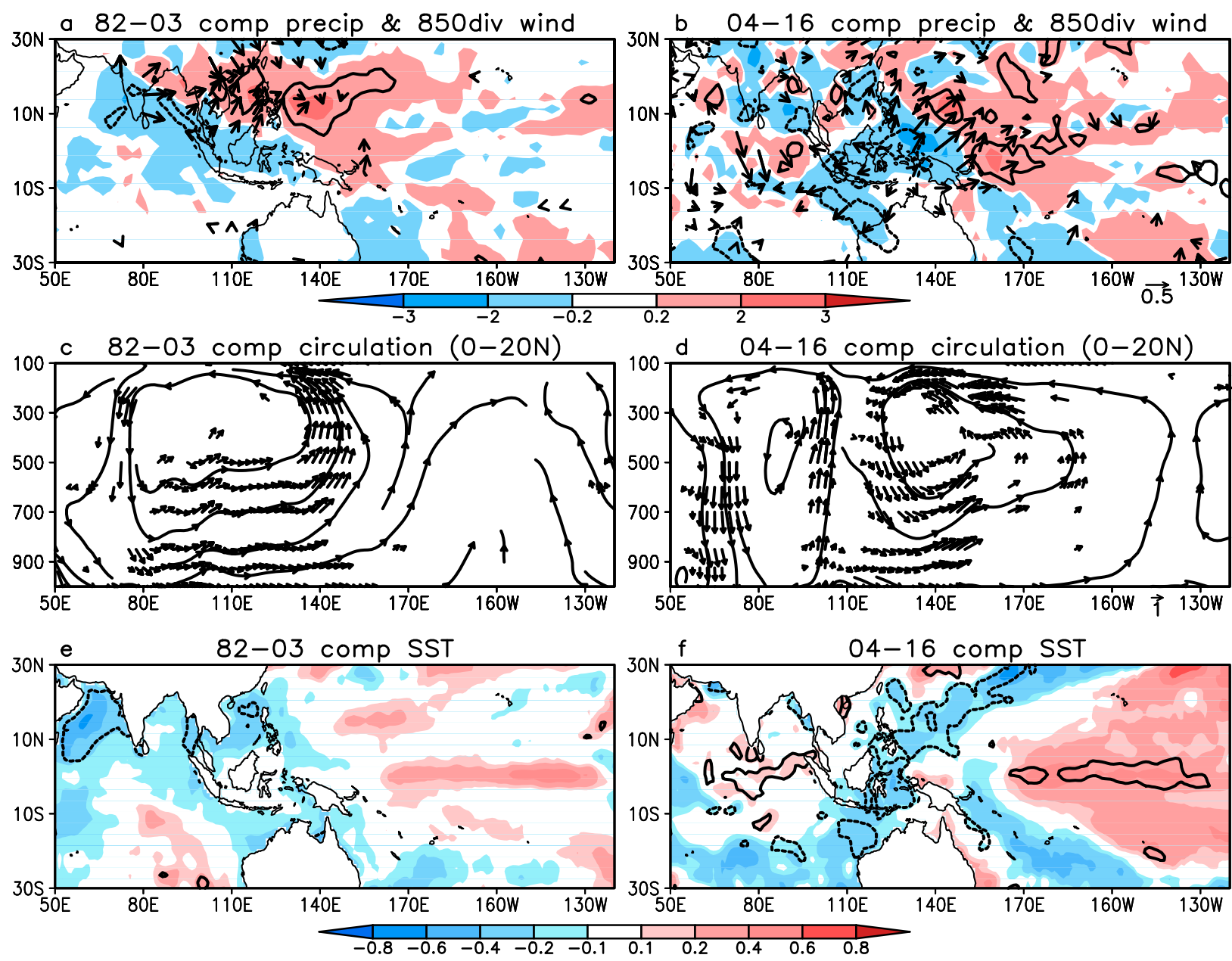

FIG. 4. Positive minus negative composite anomalies for the years with (left) same-sign and (right) opposite-sign WNP-SCS rainfall relationships during the period 1982-2003 and 2004-16: (a),(b) JJA precipitation (mm day ${ }^{-1}$; shading) and 850-hPa divergent wind ( $\mathrm{m} \mathrm{s}{ }^{-1}$; vector); (c),(d) zonal-vertical circulation averaged between $0^{\circ}$ and $20^{\circ} \mathrm{N}$ (unit: $10^{-2} \mathrm{~Pa} \mathrm{~s}^{-1}$ in vertical direction and $\mathrm{m} \mathrm{s}{ }^{-1}$ in latitudinal direction); and (e),(f) SST (K). Thick contours and vectors indicate that the composite anomalies are statistically significant at the $90 \%$ confidence level. The scale for vectors is given at the bottom right of the panels. The sign for vertical motion has been reversed so that the upward arrow denotes ascent.

calculated using positive minus negative anomaly years with respect to the WNP summer rainfall anomaly. The results are shown in Fig. 4.

In the same-sign cases, a zonal band of above-normal rainfall region extends from the SCS to the WNP (Fig. 4a). This is accompanied by lower-level cyclonic wind anomalies. Below-normal rainfall is observed over the Arabian Sea, Indian subcontinent, and southern Bay of Bengal. There are anomalous descending motion and ascending motion over $60^{\circ}-80^{\circ} \mathrm{E}$ and $110^{\circ} \mathrm{E}-180^{\circ}$, respectively, forming a west-east anomalous vertical circulation over the Indo-Pacific Ocean (Fig. 4c). Negative SST anomalies are observed in the NIO and positive SST anomalies in the Pacific Ocean (Fig. 4e). Given the correspondence of rainfall and SST anomalies, ocean cooling in the NIO and ocean warming in the CNP and CEP appear to contribute together to the rainfall and circulation anomaly pattern.

In the opposite-sign cases, a southwest-northeast rainfall anomaly pattern forms with negative and positive anomalies over the Maritime Continent and the western-central North Pacific, respectively (Fig. 4b). This is associated with anomalous lower-level divergence and convergence, respectively. Two anomalous vertical circulation cells are present. Anomalous descending motion is observed over $110^{\circ}-140^{\circ} \mathrm{E}$ and ascending motion over $140^{\circ} \mathrm{E}-160^{\circ} \mathrm{W}$ (Fig. 4d). SST anomalies are weak in the Indian Ocean (Fig. 4f). There are negative SST anomalies around the Maritime Continent and the Philippine Sea and positive SST anomalies in the tropical Pacific Ocean, respectively. It is 

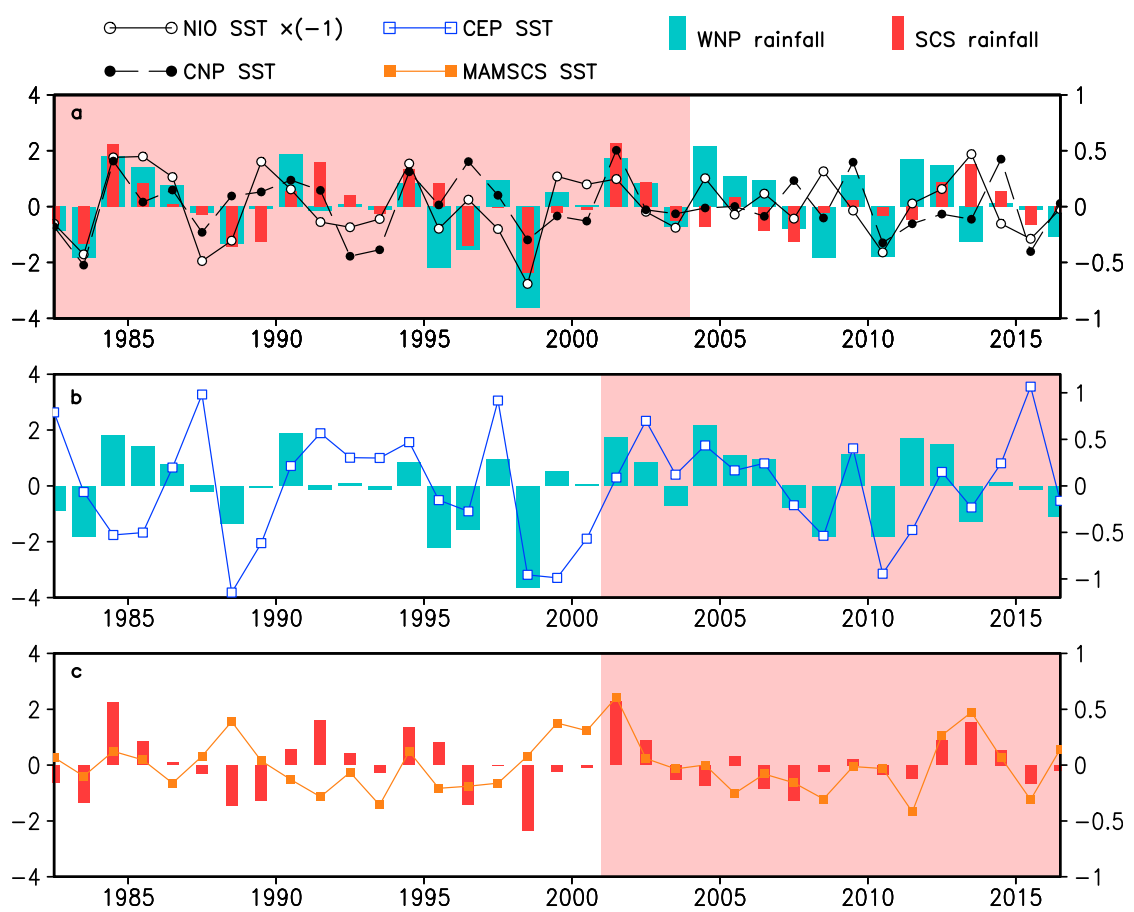

FIG. 5. Detrended time series of (a) JJA WNP precipitation anomalies ( $\mathrm{mm} \mathrm{day}^{-1}$; green column), JJA SCS precipitation anomalies ( $\mathrm{mm} \mathrm{day}^{-1}$; red column), JJA NIO SST anomalies (K; black solid curve; multiplied by -1 ), and JJA CNP SST anomalies (K; black dashed curve); (b) JJA WNP precipitation anomalies ( $\mathrm{mm} \mathrm{day}^{-1}$; green column) and JJA CEP SST anomalies (K; blue solid curve); and (c) JJA SCS precipitation anomalies (mm day ${ }^{-1}$; red column) and MAM SCS SST anomalies (K; orange solid curve) for the period 1982-2016. Scale at left is for precipitation anomalies and at right for SST anomalies. The red shading is used to distinguish the two periods - before and after the early 2000s-when the relationships between the WNP (SCS) rainfall and the SST anomalies are significantly different. The regions used to calculate the SST indices are designated with boxes in Figs. 3 and 7.

inferred that the WNP rainfall anomalies are mainly related to the SST anomalies in the tropical Pacific.

A distinct difference between these two periods is the NIO SST anomalies. This difference suggests a change in the role of the Indian Ocean anomalies, whether it works with the Pacific anomalies or not. For a detailed examination, we average the SST anomalies over the NIO, CEP, and CNP and compare them with the WNP summer rainfall anomalies in Figs. 5a and 5b. From the comparison of the time series, there is a change in the relationship between the Indian Ocean cooling and the Pacific warming around the early 2000s. The correlation coefficient between the NIO and CNP SST anomalies drops from -0.63 during 1982-2003 to -0.04 during 2004-16 (Fig. 5a). In the recent decade, the WNP rainfall variation becomes less relevant to the NIO SST anomaly compared to the previous period with a correlation coefficient decreasing from -0.73 during 1982 2003 to -0.12 during 2004-16 (Fig. 5a). In contrast, the WNP rainfall variation tends to be more consistent with the CEP SST anomaly in the recent decade than in the previous period, with a correlation coefficient increasing from 0.26 during 1982-2003 to 0.51 during 2004-16 (Fig. 5b). The change in the relationship is further elaborated in Table 1 that lists abnormal SST years with $\pm 0.3 \mathrm{~K}$ as the criterion. Before 2003/04, there are 5 out of 11 years in which both the NIO and Pacific SST forcing coexist and the WNP and SCS summer rainfall displays same-sign anomalies: 1983, 1984, 1988, 1994, and 1998. After 2003/04, no obvious NIO SST anomalies are detected among all the six abnormal WNP rainfall years. In contrast, there are three out of six cases in which the WNP rainfall anomalies coincide with the CEP SST anomalies, including the years 2004, 2006, and 2013.

The above results provide evidence that the weakening of the NIO SST forcing and the strengthening of the CEP SST forcing play an important role in altering the coherence of summer rainfall variability over the western Pacific since the early 2000s. In the prior-to-2003 epoch, the combined Indo-Pacific SST forcing may contribute to the in-phase relationship between the 

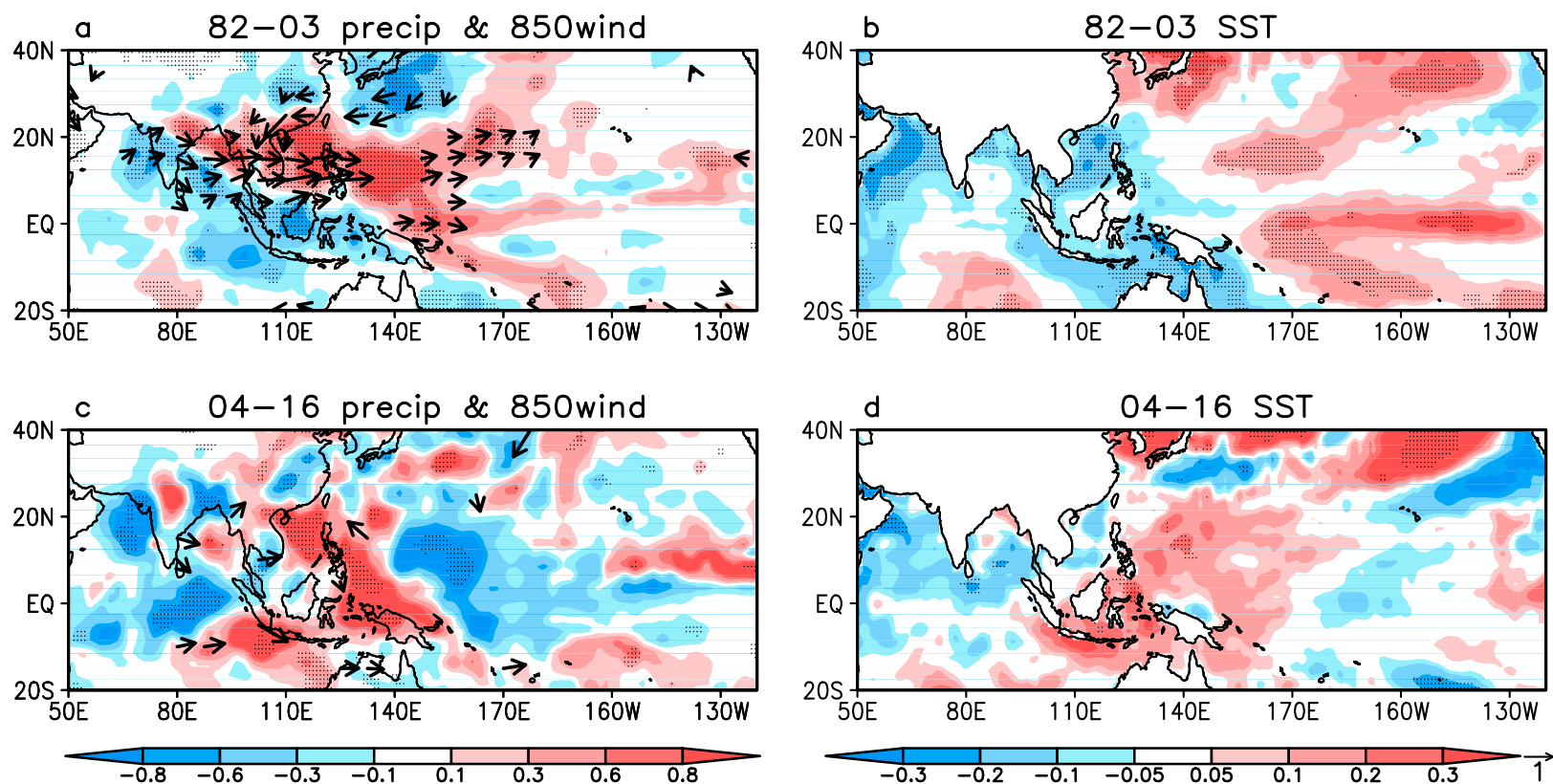

FIG. 6. As in Fig. 3, but for regression with respect to the SCS summer rainfall index.

WNP and SCS summer rainfall anomalies by inducing a zonally elongated lower-level cyclonic anomaly encompassing most of the western Pacific. In the post2004 epoch, the WNP summer rainfall may be mainly affected by enhanced Pacific forcing without the NIO SST contribution.

\section{b. Changes in the tropical ocean heating for the SCS summer rainfall}

Figure 6 displays simultaneous regressions of precipitation, lower-level wind, and SST with respect to the SCS summer rainfall anomalies. During the period 1982-2003, the rainfall, wind, and SST anomaly distributions resemble those in Figs. $3 \mathrm{a}$ and $3 \mathrm{~b}$. A tripole rainfall anomaly pattern covers the tropical Indowestern Pacific and anomalous cyclone extends from the Bay of Bengal through the SCS to the WNP (Fig. 6a) and notable SST anomalies are present in the NIO, CNP, and CEP regions (Fig. 6b). This confirms that the SCS summer rainfall anomalies have a high coherence with the WNP summer rainfall anomalies before 2003/04, and both of them are possibly under the simultaneous influence of the Indo-Pacific SST forcing.

During the period 2004-16, the rainfall and SST anomaly distributions are quite different from that in the previous period. The positive rainfall anomalies are confined to the SCS and Maritime Continent and negative rainfall anomalies are dominant over the western Pacific east of $140^{\circ} \mathrm{E}$ (Fig. 6c). This reflects that the rainfall anomalies in the SCS become independent from those in the WNP. Meanwhile, there are no large-scale wind anomalies (Fig. 6c), and positive SST anomalies appear in the Philippine Islands and around the Maritime Continent (Fig. 6d). Previous studies have indicated that both remote forcing and local coupling processes are important for the rainfall change over the SCS during the spring to summer transition seasons ( $\mathrm{Wu}$ and $\mathrm{Hu}$ 2015; $\mathrm{Hu}$ and $\mathrm{Wu} 2016$ ). Therefore, it can be preliminarily inferred that, instead of controlled by the large-scale remote forcing, the SCS summer rainfall variability may be primarily related to local processes in the recent decade.

For verification of the above inference, Fig. 7 presents the lead-lag regression of SST and precipitation with respect to the SCS summer rainfall anomalies for the periods 1982-2003 and 2004-16, respectively. During the period 2004-16, the positive SCS summer rainfall anomalies are preceded by positive SST anomalies around the SCS and Philippine Islands (Figs. 7b,d). These positive SST anomalies presumably induce positive rainfall anomalies. This local forcing is further illustrated by comparing the temporal evolution of monthly SST anomalies in the region of $2.5^{\circ}-18.5^{\circ} \mathrm{N}$, $110^{\circ}-135^{\circ} \mathrm{E}$ and monthly rainfall anomalies in the SCS region obtained by regression with respect to the JJA SCS rainfall anomalies (Fig. 7f). Corresponding to positive JJA SCS rainfall anomalies, local SST warming is observed in the preceding MAM (Fig. 7f). This anomalous warming reaches the maximum in April-May and persists into July and August. The weakening of the 

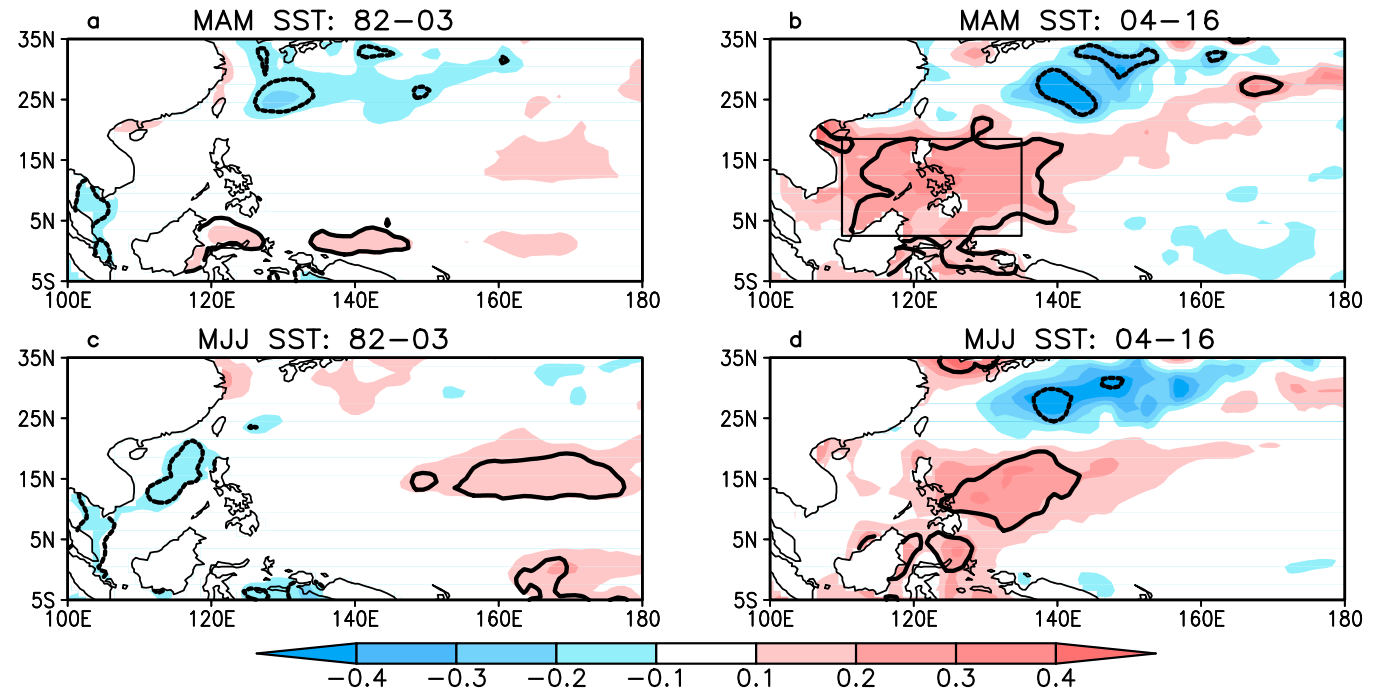

e SST*3 \& precip Re: 82-03
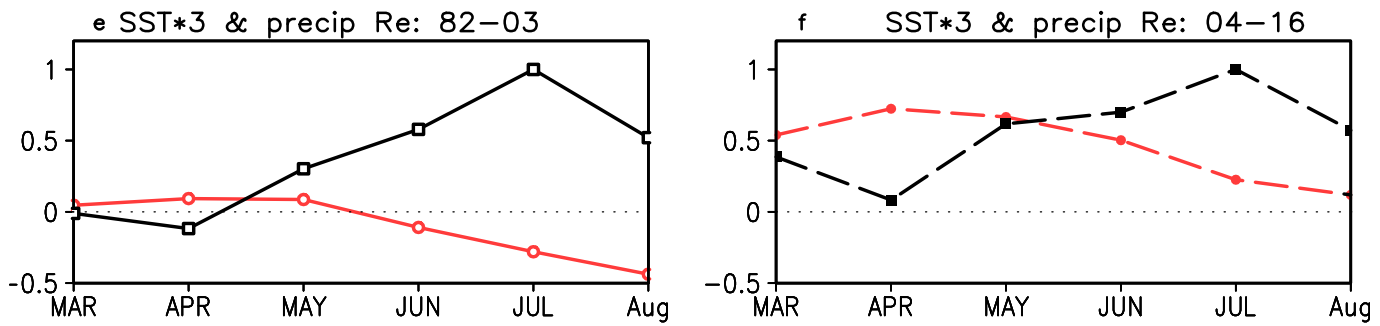

FIG. 7. Anomalies of (a),(b) MAM SST (K); (c),(d) MJJ SST (K); and (e),(f) 3-month-mean SST (K; multiplied by 3 ; red) and precipitation ( $\mathrm{mm} \mathrm{day}^{-1}$; black) averaged over the SCS obtained by regression with respect to the SCS summer rainfall index for the periods (left) 1982-2003 and (right) 2004-16. Thick contours in (a)-(d) indicate that the correlation is statistically significant at the $90 \%$ confidence level. The regions used to calculate the areamean SST and precipitation anomalies are marked with boxes in (b) $\left(2.5^{\circ}-18.5^{\circ} \mathrm{N}, 110^{\circ}-135^{\circ} \mathrm{E}\right)$ and Fig. $1 \mathrm{a}$, respectively.

positive SST anomalies may be attributed to a negative feedback of atmosphere on local SST via the windevaporation effect and cloud-radiation effect ( $\mathrm{Wu}$ and $\mathrm{Hu} 2015$; $\mathrm{Hu}$ and $\mathrm{Wu} 2016$ ). In response to this anomalous warming, the SCS rainfall is continuously enhanced from April to July (Fig. 7f). The relationship of the temporal evolution of SST and rainfall anomalies indicates local coupled processes that are characterized by a sequence of increased SST, higher rainfall, and decreased SST over the SCS (Fig. 7f). This provides evidence that the SCS summer rainfall anomaly acts as a response to local SST anomalies in the recent period.

In contrast, during the period 1982-2003, SST anomalies near the SCS are insignificant in the preceding March-May (MAM) (Fig. 7a). Instead, positive SST anomalies begin to develop over the CNP in May-July (MJJ) (Fig. 7c). The summer rainfall anomalies in the SCS are closely related to simultaneous remote influences in the Indo-Pacific Ocean as discussed in the previous section (Fig. 6b). The remote forcing drives a large-scale circulation pattern with anomalous lower-level cyclone and strengthened rainfall covering most of the western Pacific (Fig. 6a). The strengthened rainfall in the SCS, in turn, cools down local SST via reducing the incoming shortwave radiation associated with enhanced cloudiness (Fig. 7c) (He and Wu 2013). The atmospheric effect on local SST change is revealed in a temporal evolution of rainfall and SST anomalies (Fig. 7e). This atmospheric effect has been addressed in detail with a heat budget analysis by $\mathrm{He}$ and $\mathrm{Wu}$ (2013), $\mathrm{Wu}$ and $\mathrm{Hu}$ (2015), and $\mathrm{Hu}$ and $\mathrm{Wu}$ (2016). Hence, different from the recent decade in which local SST forcing drives atmospheric changes, an atmospheric damping effect of local SST may dominate over the SCS in the prior-to2003 epoch.

The changes in the remote and local SST contributions around the early 2000s are further examined using Fig. 5, which compares the SCS rainfall anomalies with SST anomalies in the CEP, CNP, NIO, and SCS. During the period 1982-2003, the SCS rainfall index displays an in-phase relationship with the CNP and CEP SST anomalies and an out-of-phase relationship with the 

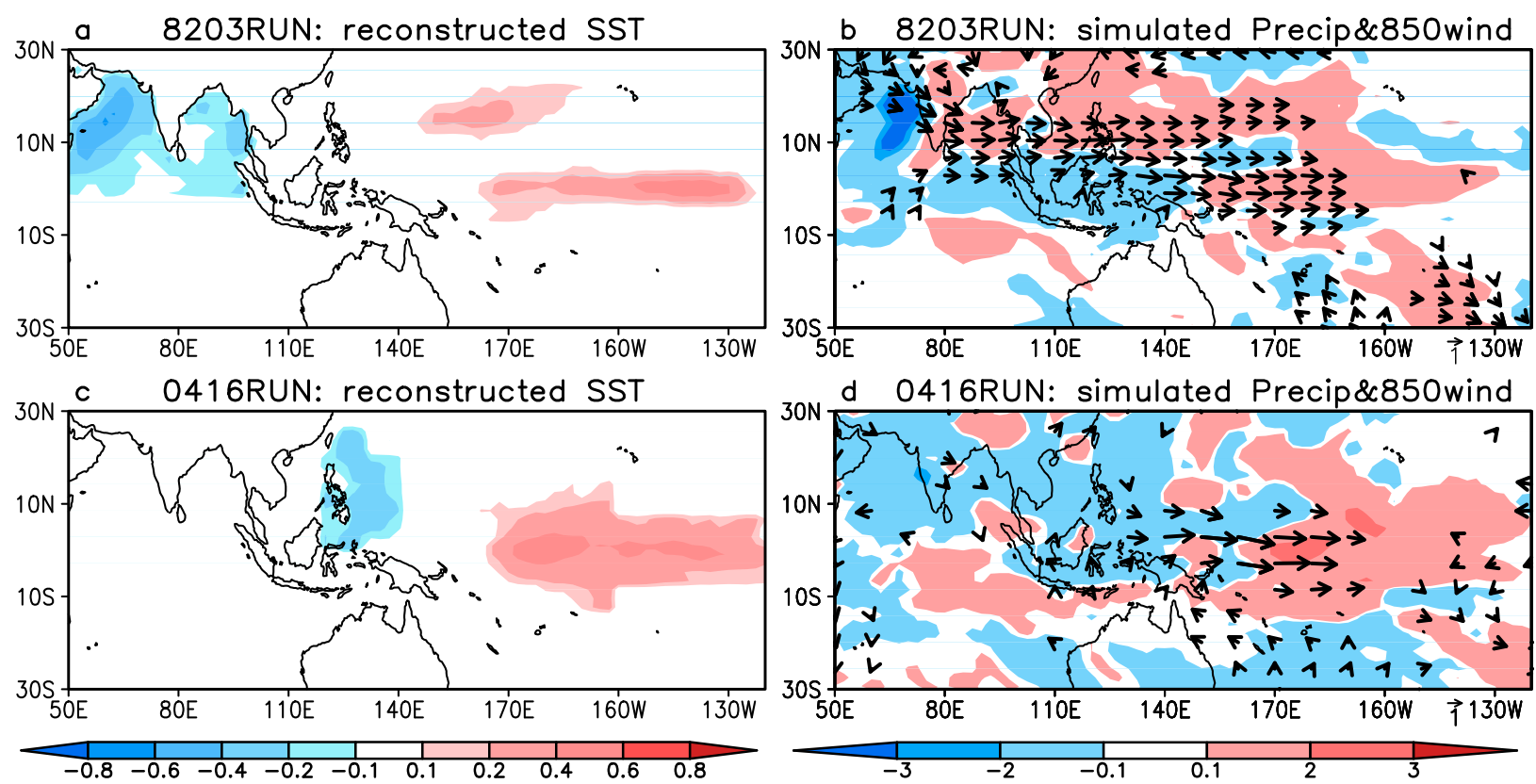

FIG. 8. (a) SST anomalies (K) specified as the lower boundary forcing in the 8203RUN, (b) the corresponding difference of JJA 850 -hPa wind ( $\mathrm{m} \mathrm{s}^{-1}$; vector) and precipitation ( $\mathrm{mm} \mathrm{day}^{-1}$; shading) between the control run and the 8203RUN, (c) SST anomalies (K) specified for the 0416RUN, and (d) the corresponding difference of JJA $850-\mathrm{hPa}$ wind ( $\mathrm{m} \mathrm{s}^{-1}$; vector) and precipitation (mm day ${ }^{-1}$; shading) between the control run and the 0416RUN. The color bars for SST and precipitation are given at the bottom, and the scales for wind vectors are given at the bottom right of the respective panels.

NIO SST anomalies (Figs. 5a,b). The correlation coefficients are $0.50,0.34$, and -0.53 , respectively. During 2004-16, the correlation coefficients with these SST indices drop to $0.14,-0.05$, and -0.36 , respectively. Meanwhile, the SCS summer rainfall tends to vary coherently with the MAM SCS SST (Fig. 5c) with a correlation coefficient of 0.78 .

The above analyses show that the local air-sea interaction process in the SCS is distinct in these two periods. During the period 1982-2003, the simultaneous remote forcing may induce precipitation anomaly, which then has a negative damping effect on local SST. During the period 2004-16, the remote forcing may become less effective and the preceding local SST forcing drives precipitation anomaly. Local air-sea interaction tends to be more important for the SCS summer rainfall variability.

\section{Numerical experiments}

Section 4 identifies the major changes in the tropical ocean forcing that may be responsible for the change in the coherence of the summer climate variability in the western Pacific since the early 2000s. In the prior-to2003 epoch, both the SCS and WNP summer rainfall anomalies are closely related to simultaneous SST anomalies in the NIO, the CNP, and the CEP. In the post-2003 epoch, the WNP rainfall anomaly exhibits an enhanced relationship with the Pacific forcing while the SCS rainfall variability is primarily associated with local SST forcing. In this section, we conduct numerical model experiments with CESM to support the observational analysis and address the proposed mechanism for this change in the climate anomaly pattern. Two groups of experiments are performed. In the first group (AGCM), the SST-forced atmospheric model (CESMCAM4) is used to compare the atmospheric response over the western Pacific to different imposed ocean forcing. In the second group (CGCM), the oceanatmosphere coupled model (CESM-CAM4+POP2) is utilized to unravel the atmospheric response to different configuration of atmosphere-ocean coupling.

\section{a. Simulations of AGCM with specific SST forcing}

In this subsection, AGCM experiments with specified SST forcing are conducted. There are three model simulations: a control simulation and two sensitivity experiments. In the control run, the atmospheric model (CESM-CAM4) is integrated for 30 years with climatological SSTs imposed in the global oceanic domain. In the first sensitivity experiment, the SST anomalies are specified in the NIO, CNP, and CEP (Fig. 8a) and climatological SSTs are prescribed in other oceanic regions. The SST forcing consists of climatological SSTs 

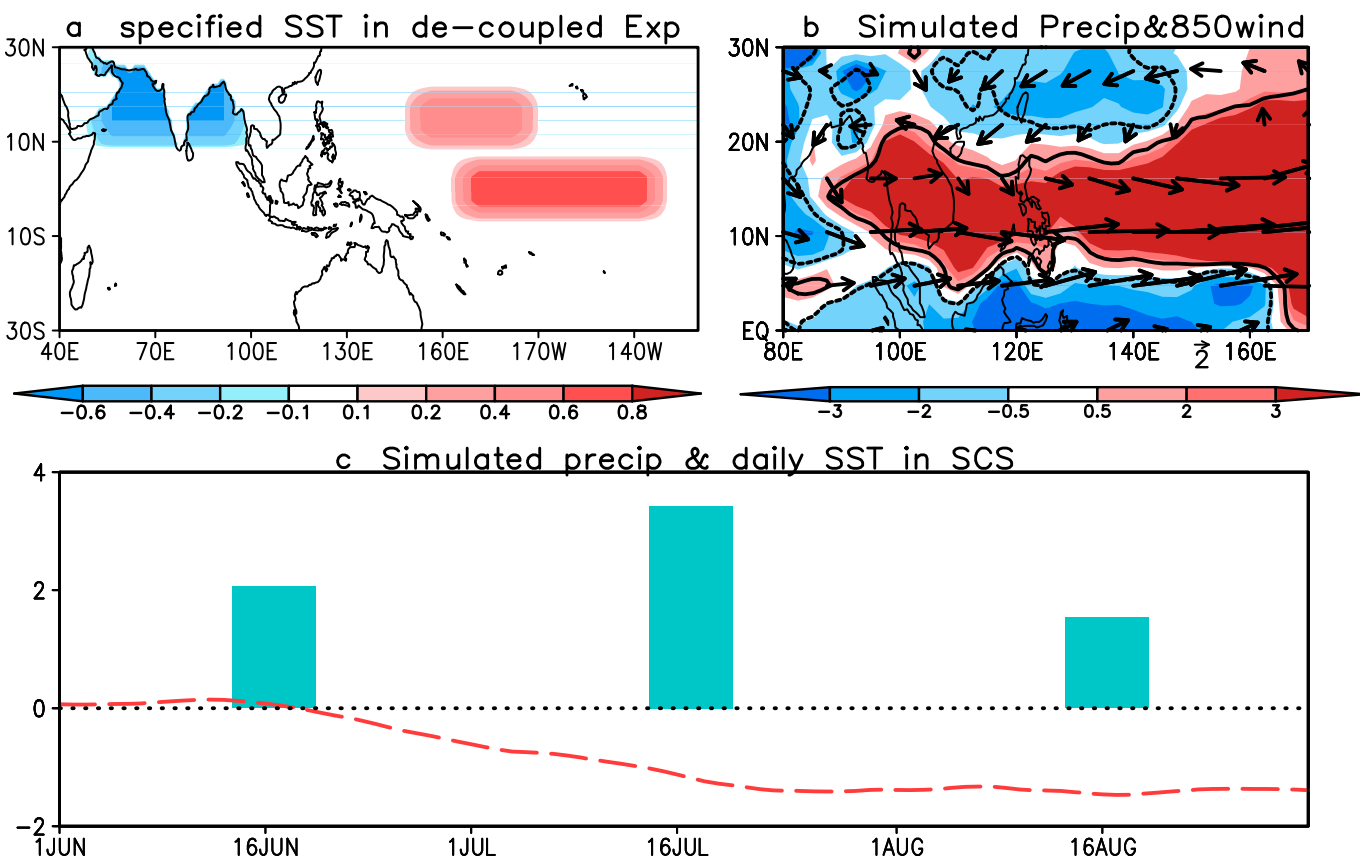

FIG. 9. (a) SST anomalies (K) specified as the lower boundary forcing in the decoupled regions from June to August in the 8203 de_cplRUN. (b) The difference of JJA-mean 850-hPa wind ( $\mathrm{m} \mathrm{s}^{-1}$; vector) and precipitation ( $\mathrm{mm} \mathrm{day}^{-1}$; shading) between the 8203 de_cplRUN and the control run. (c) The difference of monthly precipitation (mm day ${ }^{-1}$; black) and daily SST (K; red dashed) averaged over the SCS between the 8203 de_cplRUN and the control run.

and SST anomalies. The SST anomalies are based on the composite in Fig. 4e. This experiment is referred to as 8203RUN, corresponding to the case with in-phase SCS and WNP rainfall relationship. In the second sensitivity experiment, hereafter named 0416RUN, the SST anomalies are specified in the Philippine Sea and CEP region (Fig. 8c), which is based on the composite in Fig. 4f. This experiment corresponds to the case with out-of-phase SCS and WNP rainfall relationship. Both the 8203RUN and the 0416RUN cover 15-yr integration. The differences between the two sensitivity experiments and the control simulation averaged over the 15-yr integration are used to represent the atmospheric response to imposed SST anomalies. Comparison of the results in the two sensitivity experiments provides information on how the western Pacific rainfall response changes with the SST forcing.

When the negative NIO SST anomalies coexist with the positive Pacific SST anomalies (Fig. 8a), the zonally extended anomalous lower-level cyclonic circulation, negative precipitation anomalies over the NIO and the Maritime Continent, and positive precipitation anomalies over the western Pacific are reproduced well (Fig. 8b). In contrast, once the NIO anomalies are excluded and only the Pacific SST anomalies are specified with positive SST anomalies in the CEP and negative SST anomalies in the
SCS (Fig. 8c), the simulated precipitation anomalies and the associated lower-level anomalous westerlies move eastward with increased precipitation around $5^{\circ} \mathrm{S}-5^{\circ} \mathrm{N}$, $160^{\circ} \mathrm{E}-170^{\circ} \mathrm{W}$ (Fig. 8d). The north-south tripole rainfall pattern (Fig. 8b) turns into a west-east dipole pattern in the western Pacific (Fig. 8d). Accordingly, rainfall anomalies in the SCS differ from those in the WNP. The numerical model results agree with the composite anomalies in Fig. 4 although the simulated negative precipitation anomalies over the SCS in the 0416RUN are somewhat overestimated compared to the observations in Fig. 4b. The mismatch is possibly owing to (i) the difference in the structure and magnitude of the SST anomalies between the observations and the experiment; (ii) the neglect of the SST forcing around the Maritime Continent, the western South Pacific, and the equatorial Indian Ocean; or (iii) the lack of the atmospheric damping feedback in the AGCM experiment. Nonetheless, the contrast of the two experiments supports the hypothesis that the declining NIO SST forcing is possibly responsible for changes in the summer rainfall anomaly pattern in the western Pacific.

\section{b. Simulations of CGCM with regional coupling}

In this subsection, the ocean-atmosphere coupled model (CESM) is used in the numerical simulations. 

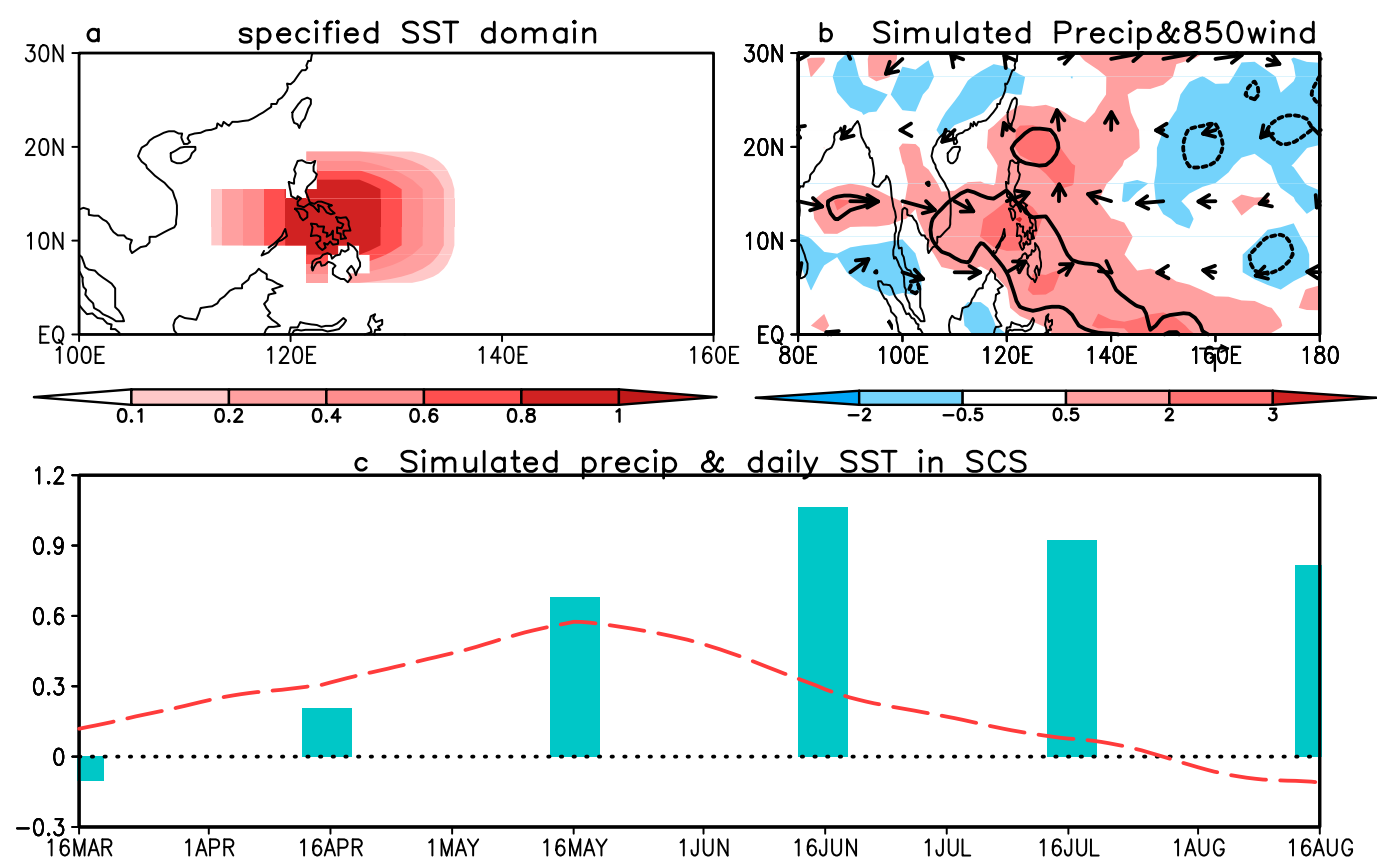

FIG. 10. (a) The domain of the decoupled region with SST forcing (K) specified from March to July in the 0416 de_cplRUN. (b) The difference of JJA-mean $850-\mathrm{hPa}$ wind $\left(\mathrm{m} \mathrm{s}^{-1}\right.$; vector) and precipitation (mm day ${ }^{-1}$; shading) between the 0416 de_cplRUN and the control run. (c) The difference of monthly precipitation ( $\mathrm{mm} \mathrm{day}^{-1}$; black) and daily SST (K; red dashed) averaged over the SCS between the 0416 de_cplRUN and the control run.

Three simulations have been conducted. The control run is integrated for 65 years with fully coupling in the global domain and the last 15 years are used for reference to conduct the sensitivity experiments. In the first sensitivity experiment, the ocean and atmosphere are fully coupled except in the CNP $\left(8^{\circ}-22^{\circ} \mathrm{N}, 145^{\circ} \mathrm{E}-170^{\circ} \mathrm{W}\right)$, CEP $\left(7^{\circ} \mathrm{S}-7^{\circ} \mathrm{N}, 160^{\circ} \mathrm{E}-130^{\circ} \mathrm{W}\right)$, and NIO $\left(5^{\circ}-25^{\circ} \mathrm{N}, 45^{\circ}-\right.$ $\left.100^{\circ} \mathrm{E}\right)$. In these regions, the oceanic and atmospheric components are decoupled with SST relaxed to climatological SST plus SST anomalies (Fig. 9a). The SST anomalies are based on the composite in Fig. 4e. The anomalous SST forcing is imposed in the model from June to August. This experiment is abbreviated as 8203 de_cplRUN, and it represents the case in which the SCS summer rainfall variability is dominated by large-scale remote influence. In the second sensitivity experiment, hereafter referred to as 0416 de_cplRUN, the atmosphere and ocean are decoupled in the SCS and the Philippine Sea regions $\left(5^{\circ}-20^{\circ} \mathrm{N}, 110^{\circ}-135^{\circ} \mathrm{E}\right)$ and the coupling is maintained in the other regions. The specified SST forcing consists of climatological SST plus $0.2 \mathrm{~K}$ in March, $0.3 \mathrm{~K}$ in April, $0.6 \mathrm{~K}$ in May, $0.4 \mathrm{~K}$ in June, and $0.3 \mathrm{~K}$ in July in the decoupled region (Fig. 10a). The anomalous SST forcing is based on the composite SST anomalies with respect to the SCS summer rainfall for the period 2004-16 (figures not shown). The second sensitivity experiment is representative of the case in which the SCS summer rainfall anomaly is modulated by local SST forcing. The 8203 de_cplRUN is integrated from June to August and the 0416 de_cplRUN is integrated from March to August each year and both experiments cover 15 years. The initial condition in the sensitivity experiments is derived from that in the control run. The differences between the sensitivity experiments and the control run averaged over the 15-yr integration are used to represent the atmospheric and oceanic response to different forcing. Figures 9 and 10 present the simulated differences between the sensitivity experiments and the control run.

Comparison of 8203 de_cplRUN with 0416 de cplRUN unfolds different regional responses in the SCS. In the 8203 de_cplRUN, the specified Indo-Pacific SST anomalies (Fig. 9a) induce a strong lower-level cyclonic anomaly, invigorating enhanced rainfall in the SCS and the WNP (Fig. 9b). In the SCS, the SST decreases following an increase in local rainfall (Fig. 9c). This simulated coupled variation in the SCS-higher rainfall followed by lower SST (Fig. 9c) - matches well with the observations (Fig. 7e). The model results confirm that the SCS rainfall anomaly is mainly due to large-scale remote forcing, and it has a damping effect on local SST in the period 1982-2003. In the 0416 de_cplRUN, remote influence has been excluded and only local forcing is imposed in the SCS (Fig. 10a). In this case, local warming is 
capable of producing rainfall anomalies over the SCS. The SCS rainfall anomaly follows well the development of SST anomaly, increasing from $-0.1 \mathrm{~mm} \mathrm{day}^{-1}$ in March to $0.9 \mathrm{~mm} \mathrm{day}^{-1}$ in August (Fig. 10c). In summer, anomalous convection is simulated over the SCS and the Philippine Sea where lower-level winds converge (Fig. 10b). This simulated relationship between local SST and precipitation agrees with the observations (Fig. 7f). The model results support the role of the preceding local SST anomalies for the SCS summer rainfall variability in the period after the early 2000 s.

\section{Summary and discussion}

The present study reveals that the coherence in the summer rainfall variability between the SCS and the WNP experienced a significant change in the early 2000s. Before 2003/04, the summer rainfall displays same-sign anomalies over the SCS and the WNP due to a control of zonally elongated anomalous lower-level cyclone/anticyclone, whereas after 2003/04 the summer rainfall variations in the two regions tend to be disparate following an eastward retreat of the anomalous lowerlevel cyclone/anticyclone. During these two periods, the extent of westward extension of the anomalous cyclone makes a great difference in regional climate in the Indochina Peninsula, southern China, South Korea, and Japan.

Observational analysis and numerical model experiments indicate that the change in the coherence of summer rainfall variations between the SCS and WNP is related to a change in the coupling between the NIO and Pacific SST forcing. Before 2003/04, the WNP circulation and rainfall variations are subject to a combined effect of the NIO and Pacific SST forcing that leads to a large zonal extension of lower-level wind and rainfall anomalies. After 2003/04, with the decline of the NIO SST forcing, the Pacific SST forcing alone is followed by an eastward retreat of lower-level wind and rainfall anomalies, resulting in dissimilar rainfall variations between the SCS and the WNP. In the recent decade, the SCS summer rainfall variations tend to be more closely related to local SST anomalies.

The present study attributes the shifted rainfall anomaly pattern in the western Pacific to changes in both remote and local influence. This finding raises another question: Why are the NIO SST contribution weakened and the Pacific SST forcing strengthened in the western Pacific rainfall variability during the recent decade? Previous studies have pointed out that El Niño/ La Niña events can induce SST anomalies in the NIO in the following summer through a series of air-sea interaction processes (Wu et al. 2008; Du et al. 2009; Xie et al. 2010; He and Wu 2014). Meanwhile, growing evidence shows that the global surface warming is experiencing a hiatus period since the end of the twentieth century, characterized by a La Niña-like SST anomaly pattern with SST cooling in the eastern tropical Pacific (Knight et al. 2009). It is also noticed that there is an increase in the frequency of central Pacific El Niño events since the late twentieth century (Yeh et al. 2009; Lee and McPhaden 2010; Yeh et al. 2011). Changes in the ENSO characteristics-the frequency, the amplitude, the seasonal phase, the spatial pattern, or the coupling processes-may lead to different global climate teleconnections (Yeo et al. 2012; Hu et al. 2016). Hence, there is one implication that the weakened relationship between the JJA NIO SST and the western Pacific rainfall may be likely related to changes in ENSO remote influence. Does the change in the ENSO characteristics play a role in altering the Indo-Pacific forcing of the western Pacific climate variability or not, and what is the potential physical mechanism? Analysis is in progress and this issue will be addressed in detail in a forthcoming study.

Acknowledgments. This study is supported by the National Key Basic Research Program of China (Grant 2014CB953902), the National Natural Science Foundation of China (Grants 41506003, 41530425, 41676013, 41731173, and 41776023), and the Independent Research Project Program of State Key Laboratory of Tropical Oceanography (LTOZZ1603). The NOAA IO v2 SST, GPCP version 2.2 precipitation, NCEP-DOE Reanalysis 2, and NCEP GODAS data are obtained from http://www.esrl.noaa.gov/psd/data.

\section{REFERENCES}

Adler, R. F., and Coauthors, 2003: The version-2 Global Precipitation Climatology Project (GPCP) monthly precipitation analysis (1979-present). J. Hydrometeor., 4, 11471167, https://doi.org/10.1175/1525-7541(2003)004<1147: TVGPCP $>2.0 . \mathrm{CO} ; 2$.

Chang, C.-P., Y. Zhang, and T. Li, 2000: Interannual and interdecadal variations of the East Asian summer monsoon and tropical Pacific SSTs. Part I: Roles of the subtropical ridge. J. Climate, 13, 4310-4325, https://doi.org/10.1175/ 1520-0442(2000)013<4310:IAIVOT>2.0.CO;2.

Du, Y., S.-P. Xie, G. Huang, and K. Hu, 2009: Role of air-sea interaction in the long persistence of El Niño-induced north Indian Ocean warming. J. Climate, 22, 2023-2038, https:// doi.org/10.1175/2008JCLI2590.1.

Eaton, B., 2012: User's guide to the Community Atmosphere Model CAM-5.1.1. NCAR, 32 pp., http://www.cesm.ucar.edu/ models/cesm1.0/cam/docs/ug5_1_1/ug.pdf.

Gill, A., 1980: Some simple solutions for heat-induced tropical circulation. Quart. J. Roy. Meteor. Soc., 106, 447-462, https:// doi.org/10.1002/qj.49710644905. 
He, Z., and R. Wu, 2013: Seasonality of interannual atmosphereocean interaction in the South China Sea. J. Oceanogr., 69, 699-712, https://doi.org/10.1007/s10872-013-0201-9.

- , and —, 2014: Indo-Pacific remote forcing in summer rainfall variability over the South China Sea. Climate Dyn., 42, 2323-2337, https://doi.org/10.1007/s00382-014-2123-7.

—_ - and W. Wang, 2016: Signals of the South China Sea summer rainfall variability in the Indian Ocean. Climate Dyn., 46, 3181-3195, https://doi.org/10.1007/s00382-015-2760-5.

Hu, C., S. Yang, Q. Wu, Z. Li, J. Chen, K. Deng, T. Zhang, and C. Zhang, 2016: Shifting El Niño inhibits summer Arctic warming and Arctic sea-ice melting over the Canada Basin. Nat. Commun., 7, 11721, https://doi.org/10.1038/ncomms11721.

$\mathrm{Hu}, \mathrm{W}$., and R. Wu, 2016: Air-sea interaction in association with monthly anomaly departure over the western North Pacific and tropical Indian Ocean during the spring-to-summer transition. J. Climate, 29, 2095-2108, https://doi.org/10.1175/ JCLI-D-15-0461.1.

,$- \ldots$, and Y. Liu, 2014: Relation of the South China Sea precipitation variability to tropical Indo-Pacific SST anomalies during spring-to-summer transition. J. Climate, 27, 54515467, https://doi.org/10.1175/JCLI-D-14-00089.1.

Huang, R. H., and F. Sun, 1992: Impacts of the tropical western Pacific on the East Asian summer monsoon. J. Meteor. Soc. Japan, 70, 243-256, https://doi.org/10.2151/jmsj1965.70.1B_243.

Kanamitsu, M., W. Ebisuzaki, J. Woollen, S. K. Yang, J. J. Hnilo, M. Fiorino, and G. L. Potter, 2002: NCEP-DOE AMIP-II Reanalysis (R-2). Bull. Amer. Meteor. Soc., 83, 1631-1644, https://doi.org/10.1175/BAMS-83-11-1631.

Knight, J., and Coauthors, 2009: Do global temperature trends over the last decade falsify climate predictions [in "State of the Climate in 2008'"]. Bull. Amer. Meteor. Soc., 90 (8), S22S23, https://journals.ametsoc.org/doi/pdf/10.1175/BAMS90-8-StateoftheClimate.

Lee, T., and M. J. McPhaden, 2010: Increasing intensity of El Niño in the central-equatorial Pacific. Geophys. Res. Lett., 37, L14603, https://doi.org/10.1029/2010GL044007.

Lindzen, R. S., and S. Nigam, 1987: On the role of sea surface temperature gradients in forcing low-level winds and convergence in the tropics. J. Atmos. Sci., 44, 2418-2436, https://doi.org/ 10.1175/1520-0469(1987)044<2418:OTROSS >2.0.CO;2.

Matsuno, T., 1966: Quasi-geostrophic motions in the equatorial area. J. Meteor. Soc. Japan, 44, 25-43, https://doi.org/10.2151/ jmsj1965.44.1_25.

Nitta, T., 1987: Convective activities in the tropical western Pacific and their impact on the Northern Hemisphere summer circulation. J. Meteor. Soc. Japan, 65, 373-390, https://doi.org/ 10.2151/jmsj1965.65.3_373.

Reynolds, R. W., N. A. Rayner, T. M. Smith, D. C. Stokes, and W. Wang, 2002: An improved in situ and satellite SST analysis for climate. J. Climate, 15, 1609-1625, https://doi.org/10.1175/ 1520-0442(2002)015<1609:AIISAS > 2.0.CO;2.

Smith, R., and Coauthors, 2010: The Parallel Ocean Program (POP) reference manual: Ocean component of the Community Climate System Model (CCSM). Los Alamos National Laboratory Tech. Rep. LAUR-10-01853, 141 pp., http://www.cesm.ucar. edu/models/cesm1.0/pop2/doc/sci/POPRefManual.pdf.

Vertenstein, M., T. Craig, A. Middleton, D. Feddema, and C. Fischer, 2011: CESM1.0.4 User's Guide. NCAR, 146 pp., http://www.cesm.ucar.edu/models/cesm1.0/cesm/cesm_doc_ 1_0_4/x42.html.
Wang, B., and Q. Zhang, 2002: Pacific-East Asian teleconnection. Part II: How the Philippine Sea anomalous anticyclone is established during El Niño development. J. Climate, 15, 3252-3265, https://doi.org/10.1175/1520-0442(2002)015<3252: PEATPI $>2.0 . \mathrm{CO} ; 2$.

— R. Wu, and X. Fu, 2000: Pacific-East Asian teleconnection: How does ENSO affect East Asian climate? J. Climate, 13, 1517-1536, https://doi.org/10.1175/1520-0442(2000)013<1517: PEATHD $>2.0 . \mathrm{CO} ; 2$.

- _ - and K.-M. Lau, 2001: Interannual variability of the Asian summer monsoon: Contrasts between the Indian and western North Pacific-East Asian monsoons. J. Climate, 14, 4073-4090, https://doi.org/10.1175/1520-0442(2001)014<4073: IVOTAS $>2.0 . \mathrm{CO} ; 2$.

Wu, R., and B. Wang, 2002: A contrast of the East Asian summer monsoon-ENSO relationship between 1962-77 and 1978-93. J. Climate, 15, 3266-3279, https://doi.org/10.1175/ 1520-0442(2002)015<3266:ACOTEA > 2.0.CO;2.

_- , and B. P. Kirtman, 2007: Regimes of local air-sea interactions and implications for performance of forced simulations. Climate Dyn., 29, 393-410, https://doi.org/10.1007/ s00382-007-0246-9.

_ precipitation anomaly change and mean precipitation anomaly over the South China Sea and the Arabian Sea during the spring to summer transition. J. Climate, 28, 7161-7181, https:// doi.org/10.1175/JCLI-D-15-0136.1.

_ , and Z. He, 2017: Two distinctive processes for abnormal spring to summer transition over the South China Sea. J. Climate, $\mathbf{3 0}$, 9665-9678, https://doi.org/10.1175/JCLI-D-17-0215.1.

—_, Z.-Z. Hu, and B. P. Kirtman, 2003: Evolution of ENSOrelated rainfall anomalies in East Asia. J. Climate, 16, 37423758, https://doi.org/10.1175/1520-0442(2003)016<3742: EOERAI > 2.0.CO;2.

_ B. P. Kirtman, and V. Krishnamurthy, 2008: An asymmetric mode of tropical Indian Ocean rainfall variability in boreal spring. J. Geophys. Res., 113, D05104, https://doi.org/10.1029/ 2007JD009316.

_ - G. Huang, Z. Du, and K. Hu, 2014: Cross-season relation of the South China Sea precipitation variability between winter and summer. Climate Dyn., 43, 193-207, https://doi.org/ 10.1007/s00382-013-1820-y.

Xie, S.-P., K. Hu, J. Hafner, H. Tokinaga, Y. Du, G. Huang, and T. Sampe, 2009: Indian Ocean capacitor effect on Indo-western Pacific climate during the summer following El Niño. J. Climate, 22, 730-747, https://doi.org/10.1175/ 2008JCLI2544.1.

—, Y. Du, G. Huang, X. T. Zheng, H. Tokinaga, K. Hu, and Q. Liu, 2010: Decadal shift in El Niño influences on Indowestern Pacific and East Asian climate in the 1970s. J. Climate, 23, 3352-3368, https://doi.org/10.1175/2010JCLI3429.1.

Yeh, S.-W., J.-S. Kug, B. Dewitte, M.-H. Kwon, B. P. Kirtman, and F.-F. Jin, 2009: El Niño in a changing climate. Nature, 461, 511-514, https://doi.org/10.1038/nature08316.

_ B. P. Kirtman, J. S. Kug, W. Park, and M. Latif, 2011: Natural variability of the central Pacific El Niño event on multicentennial timescales. Geophys. Res. Lett., 38, L02704, https://doi.org/10.1029/2010GL045886.

Yeo, S. R., K. Y. Kim, S. W. Yeh, and W. Kim, 2012: Decadal changes in the relationship between the tropical Pacific and the North Pacific. J. Geophys. Res., 117, D15102, https:// doi.org/10.1029/2012JD017775. 